\title{
A Prospective Study and Analysis of Ventriculoperitoneal Shunt Surgery: Their Indication and Complication in a Single Tertiary Care Center
}

\author{
${ }^{1}$ Department of Anesthesia, Jagannath Gupta Institute of Medical \\ Sciences, Budge Budge, Kolkata, West Bengal, India \\ ${ }^{2}$ Department of Neurosurgery, IMS-BHU, Varanasi, Uttar Pradesh, \\ India \\ ${ }^{3}$ Department of Anesthesiology, IMS-BHU, Varanasi, Uttar Pradesh, \\ India \\ ${ }^{4}$ Junior Resident, IMS-BHU, Varanasi, Uttar Pradesh, India \\ ${ }^{5}$ Department of Neurosurgery, Dr. RPGMC, Kangra, Himachal \\ Pradesh, India
}

Barnava Pal ${ }^{1}$ Sambuddha Dhar ${ }^{2}$ Anurag Sahu ${ }^{2}$ Sumita Kumari ${ }^{3} \quad$ Kulwant Singh $^{2}$ Kamalpreet Kaur Bhaikhel ${ }^{4}$ Shrish Nalin ${ }^{5}$ Ashvamedh Singh ${ }^{2}$ Rahul Singh ${ }^{2}$

\begin{abstract}
Address for correspondence Sumita Kumari, MBBS, MD, Department of Anesthesiology, Mahamaya Rajkiya Allopathic Medical College, Saddarpur, Akabarpur-Tanda Road, P. O. Surapur, Ambedkarnagar, Uttar Pradesh 224227, India (e-mail: drsumita.1@gmail.com).
\end{abstract}

Indian J Neurosurg 2022;11:153-158

\begin{abstract}
Keywords

- ventriculoperitoneal shunt

- hydrocephalus

- shunt complications

Background Ventriculoperitoneal (VP) shunt insertion is routinely performed for the treatment of hydrocephalus due to different indications like congenital, infective, tumor, posttraumatic, and normal pressure hydrocephalus (NPH). A lot of common and rare complications following this procedure have been reported.

Objectives To analyze the clinical profile, indications, anesthetic, and postoperative complications for VP shunt surgery in our center.

Materials and Methods This prospective clinical review study was conducted in the Department of Neurosurgery, Institute of Medical Sciences, Banaras Hindu University, Varanasi, between October 2018 to January 2020 and included 454 cases of hydrocephalus who underwent VP shunt surgery. The data was compiled and analyzed.

Results A total of 454 patients with male predominance were studied. Pediatric and adolescent patients were $48.9 \%$ (222/454). Obstructive hydrocephalus due to tumors was the etiology of $48.7 \%(221 / 454)$ cases. The incidence of overall shunt complications was $9.7 \%(44 / 454)$, of which obstruction and infection was 5.9\% (27/454) and $3.1 \%(14 / 454)$, respectively. Factors associated with increased shunt complications include redo and infective etiology and cases having higher protein in perioperative cerebrospinal fluid (CSF) analysis. Neuronavigation, antibiotic-impregnated shunt and biventricular shunt are associated with lower complications.

Conclusion Obstructive hydrocephalus due to tumors happened to be the most common cause of VP shunt, and shunt obstruction is most common complication, especially in infective and redo cases.
\end{abstract}

published online

May 13, 2021
DOI https://doi.org/

$10.1055 / \mathrm{s}-0041-1726814$ ISSN 2277-954X (c)2021. Neurological Surgeons' Society of India.

This is an open access article published by Thieme under the terms of the Creative Commons Attribution-NonDerivative-NonCommercial-License, permitting copying and reproduction so long as the original work is given appropriate credit. Contents may not be used for commercial purposes, or adapted, remixed, transformed or built upon. (https://creativecommons.org/licenses/by-nc-nd/4.0/).

Thieme Medical and Scientific Publishers Pvt. Ltd. A-12, 2nd Floor, Sector 2, Noida-201301 UP, India 


\section{Introduction}

A ventriculoperitoneal (VP) shunt is a cerebral shunt which drains excess cerebrospinal fluid (CSF) into the peritoneal cavity, when there is an obstruction in the normal outflow or a decreased absorption of CSF. ${ }^{1}$ Cerebral shunts are the mainstay of treatment for hydrocephalus. ${ }^{2}$ VP shunt placement is a very commonly performed neurosurgical procedure. ${ }^{3}$ There are various etiologies for shunt placement-congenital, infective, tumor, posttraumatic, normal pressure hydrocephalus (NPH), etc. ${ }^{4}$

From the anesthetic point of view, VP shunt insertion provides various challenges related to difficult airway, already compromised cerebral physiology, and control of intracranial pressure (ICP) during periods of stimulation such as intubation and tunneling of shunt. ${ }^{5}$

Postoperative complication rates of this procedure remain considerably high. VP shunt failure rates have been found at approximately 11 to $25 \%$ within the first year of shunt placement. The most common causes of shunt failure are shunt obstruction, followed by infection. ${ }^{6.7}$ Infections are the major cause of early shunt failures and catheter occlusions are the major cause of late shunt failures. ${ }^{8}$ Other complication includes catheter migration, bowel perforation, pseudocyst formation, subdural hematoma formation, hemiplegia, etc., ${ }^{9,10}$

We undertook a prospective data analysis of all the cases of VP shunt surgery over a period of about one and half year done in the Department of Neurosurgery, Institute of Medical Sciences, Banaras Hindu University, Varanasi, which is a tertiary care center. This single hospital-based epidemiological study, being one of its kind, will hopefully serve the purpose of analyzing various indication and complications of VP shunt surgery in the given population.

\section{Aims}

The aim of this study is to analyze the clinical profile, indications, and anesthetic and postoperative complications of VP shunt surgery in our center and also study factors influencing shunt complications.

\section{Materials and Methods}

This study was conducted in the Department of Neurosurgery, Institute of Medical Sciences, Banaras Hindu University, Varanasi, between October 2018 to January 2020 and included 454 cases of hydrocephalus who underwent VP shunt surgery.

Inclusion criteria: Patients of all age groups and both gender presenting in our hospital having CT-proven hydrocephalus requiring VP shunt; Glasgow coma scale (GCS) 9 to 15.

Exclusion Criteria: Presence of active bacterial and tubercular meningitis, presenting as hydrocephalus; patients with slit ventricles assessed on CT scan brain; altered coagulation profile.

All the patients were admitted after clinical assessment under a standard medical protocol and subjected to basic hematochemical and radioimaging evaluation. After preanesthetic checkup, patients were posted for VP shunt surgery. General anesthesia was used in all cases and any perioperative complication was noted down. Chhabra's medium pressure shunt was used in all patients and Keen's point was used as catheter entry point except in NPH patients where either low-pressure shunts or programmable shunts were used. Antibiotic-impregnated shunt was used in some cases and neuronavigation also used in few cases to accurately place the shunt tip. CSF collected during the surgery was sent for analysis. Assessment of shunt functioning was done by taking the following points into consideration:
(a) History of headache, vomiting, convulsions.
(b) Neurological examination including vision, motor, sen- sory system.
(c) Local examination-Inspection and palpation of shunt system, and testing of shunt pump for refill.
(d) CT scan.

Shunt revision was considered if earlier VP shunt was malfunctioning. Revision was done on same or other side. Cases were investigated, managed, and followed accordingly. Patients who died during the 3-month follow-up period was excluded from the study.

The data was compiled and analyzed. We performed prospective clinical review, which was subjected to statistical analysis using statistical package for the social sciences (SPSS) version 25 software. Chi-square, student's $t$-test, and logistic regression analysis were used wherever applicable.

\section{Results}

In our study, we studied total 454 patients, out of which $62.8 \%$ (285/454) were males and 37.2\% females (169/454). Pediatric and adolescent patients formed the majority with $48.9 \%$ (222/454) cases, of which < 5 -year patients consisted of $21.4 \%$ (97/454). A significant number (170/454-37.4\%) of patients were middle aged (between 18 to 50 years of age). Only $13.7 \%$ (62/454) were above 50 years of age.

As much as $10.4 \%(47 / 454)$ patients were redo cases because of complications which were not manageable by nonsurgical methods. As much as 53.2\% (25/47) patients among them were operated due to shunt obstruction.

Obstructive hydrocephalus due to tumors happened to be the most common cause of VP shunt surgery (221/454-48.7\%), followed by nonobstructive hydrocephalus due to infective causes (121/454-26.7\%), among which tuberculous meningitis (TBM) was the most common. As much as $4 \%(18 / 454)$ of cases were NPH. Trauma also happened to a minor cause of VP shunt with only $4.4 \%$ (20/454). Congenital hydrocephalus consists of $10.8 \%$ (49/454) of patients. - Table 1 shows various etiologies of VP shunt surgery and $\boldsymbol{-}$ Fig. 1 shows a postoperative CT scan of congenital hydrocephalus with shunt.

In 33/454 cases (7.3\%), biventricular shunting was done, which were suprasellar tumors causing foramen of Monroe blockage. Craniopharyngioma was the most common among them. Majority (344/454-77.9\%) shunts were inserted on the right side because of nondominant hemisphere. In the remaining cases, left-sided shunt was inserted where the 
Table 1 Relation between etiology and complication of VP shunt

\begin{tabular}{|l|l|l|l|l|l|}
\hline Etiology/complications & Nil & Obstruction & Displacement & Infection & Total \\
\hline Congenital & 49 & 0 & 0 & 0 & 49 \\
\hline Infection & 106 & 6 & 0 & 9 & 121 \\
\hline Malfunction & 3 & 17 & 3 & 2 & 25 \\
\hline NPH & 18 & 0 & 0 & 0 & 18 \\
\hline Post-traumatic & 20 & 0 & 0 & 0 & 20 \\
\hline Tumor & 214 & 4 & 0 & 3 & 221 \\
\hline Total & 410 & 27 & 3 & 14 & 454 \\
\hline
\end{tabular}

Abbreviation: VP, ventriculoperitoneal.

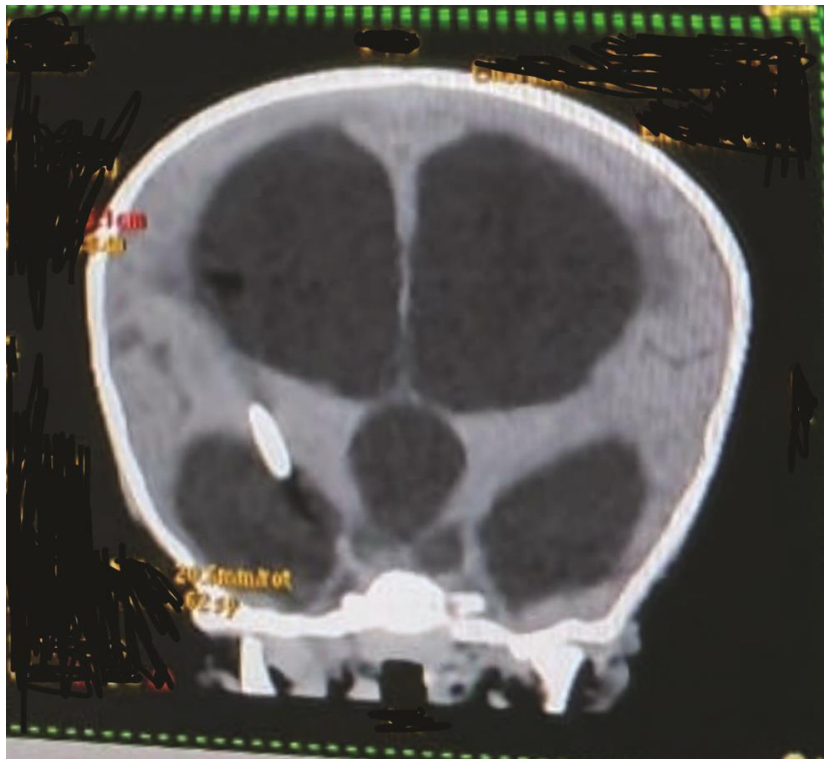

Fig. 1 Postoperative CT scan of congenital hydrocephalus with shunt.

tumors were localized on the right side or in redo cases where the right-sided VP shunting was infected.

CSF protein was analyzed in all the cases postoperatively. As much as $48.7 \%(221 / 454)$ cases had elevated CSF protein.

In $24.7 \%$ (112/454) patients, surgery was done under navigation guidance to accurately place the shunt tip of the ventricular end at the ipsilateral frontal horn. Due to time limitation and cost, rest $75.3 \%$ (342/454) were done using simple blind technique through Keen's point. - Fig. 2 shows wrong trajectory of the shunt, which was done using the conventional method. Fortunately, this patient did not have any focal neurodeficit. Similarly, antibiotic-impregnated shunt was used in 26\% (118/454) cases. Anesthetic complication includes difficulty in intubation, intraoperative hemodynamic instability, and postoperative delayed emergence. There were no documented major anesthetic complications during the surgery.

As much as $90.3 \%$ (410/454) of patients had no shunt-related postoperative complications at 3 months follow-up. But 5.9\% (27/454) of cases had shunt blockage and 3.1\% (14/454) of patients had infection either at the abdominal site with pus discharge or shunt tract infection. Among the obstruction

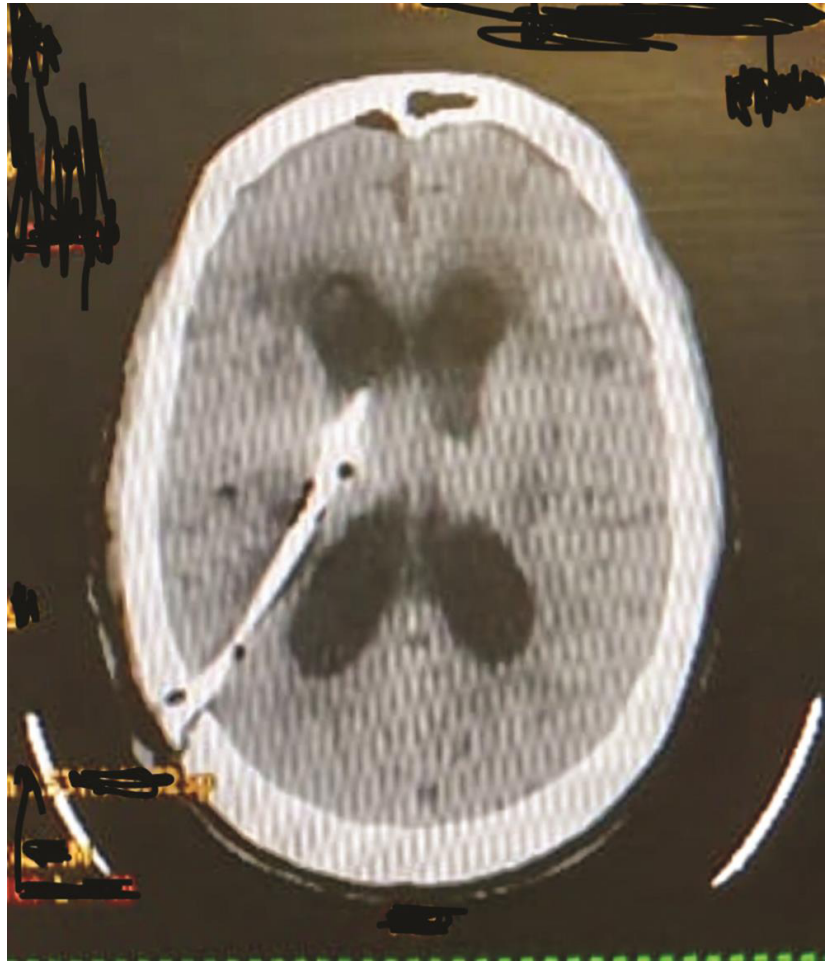

Fig. 2 Wrong trajectory of shunt, using conventional method.

cases, 72\% (19/27) cases obstruction was proximal and remaining (8/27) had abdominal end obstruction. Among the distal obstruction cases, seven had shunt tips in the subcutaneous plane, and only one had distal obstruction due to unknown causes. - Fig. 3 shows a shunt obstruction, which had dilated ventricles. Only three cases had distal migration of the shunt. Among them, distal catheter tip was migrated in the abdominal incision site after eroding the skin in two cases. - Fig. 4 shows shunt migration at the abdominal incision site. Another case had migration through the rectum. - Table 1 shows all complication along with etiologies.

None of congenital, posttraumatic, and NPH cases had any postoperative complications. A total of 15 patients (12.4\%) among the 121 infective causes had complications, among which 6 patients had shunt block and rest had an infection. Among 25 redo cases, 17 (68\%) patients had repeat shunt blockade. Complication rates were similar in both the sexes. 


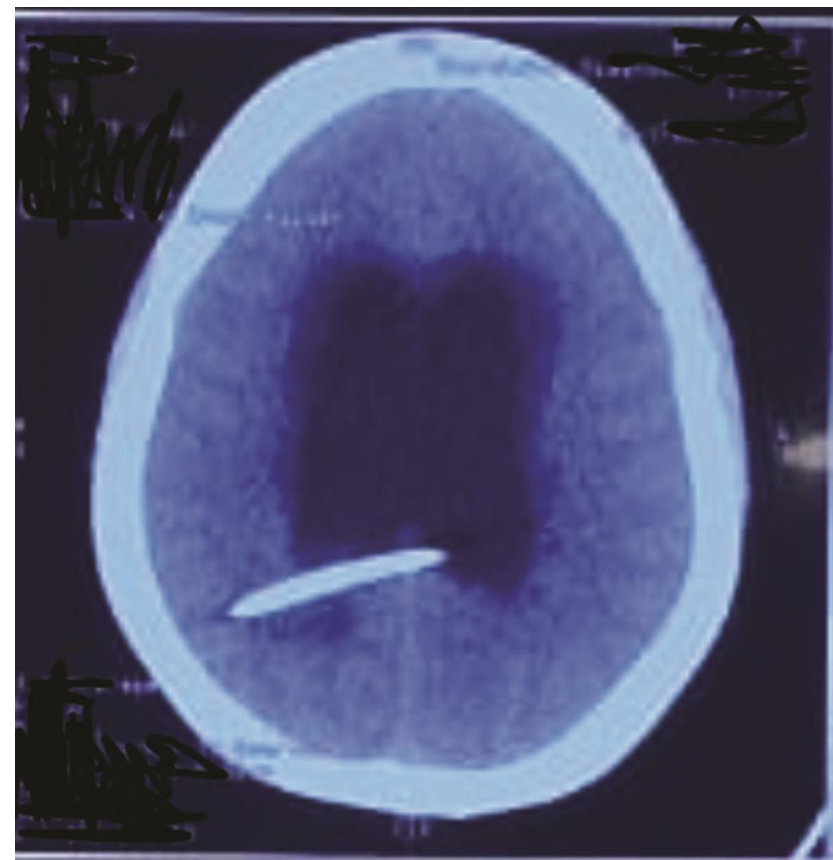

Fig. 3 Shunt obstruction.

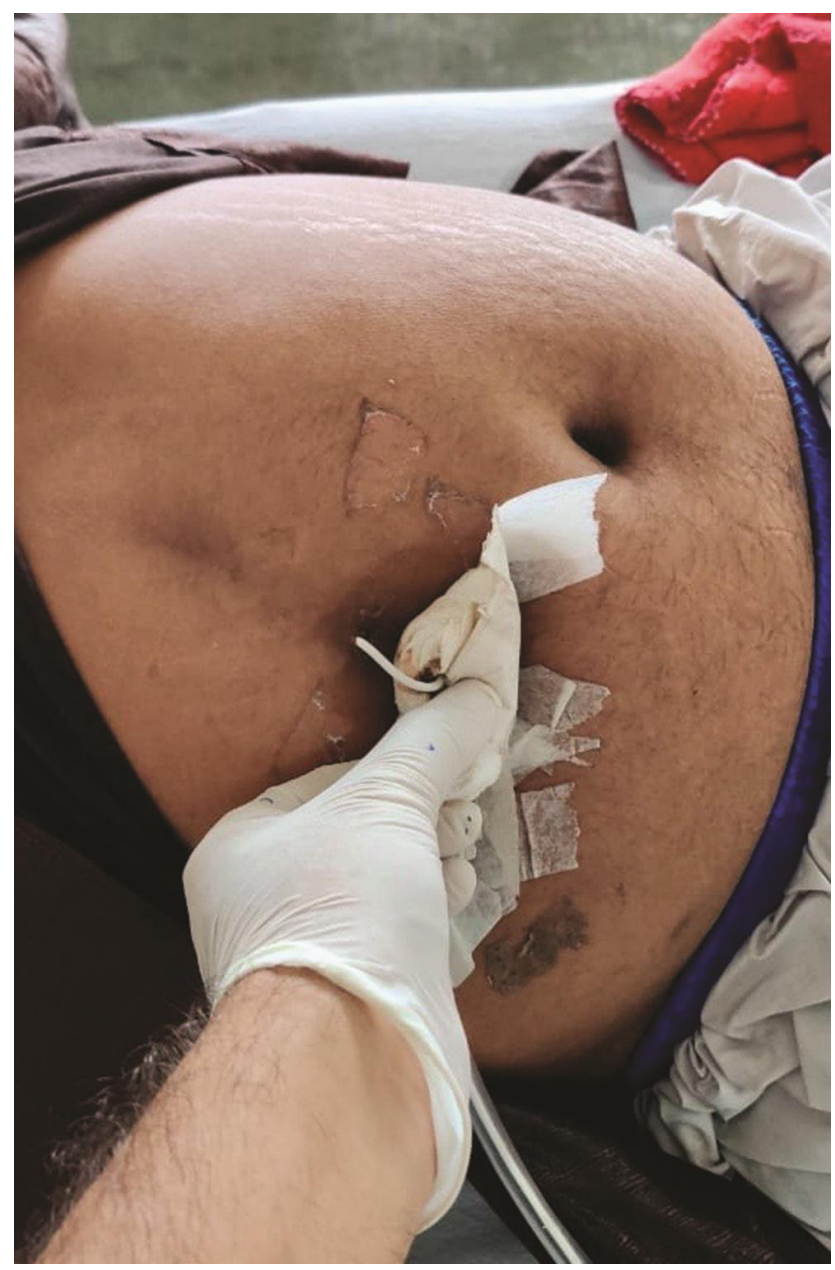

Fig. 4 Shunt migration at the abdominal incision site.
None of the biventricular shunt patients (33/454) had any complications, but among the single-sided shunt, left-sided had $34 \%$ (23/67) had more infection by percentage and less on right side (5.9\%; 21/355), although this was a statistically insignificant finding.

Among 112 patients who underwent shunting with navigation-guided approach, only one patient had block and three had postoperative infection, both are significantly less $(p<0.05)$ than conventionally done surgery. Patients having higher protein in perioperative CSF analysis had a higher incidence of shunt blockade; again, a statistically significant finding. None of our patients had any postoperative focal neurological deficit.

\section{Discussion}

This study included all the operated cases of VP shunt surgery admitted to the Institute of Medical Sciences, Banaras Hindu University, Varanasi, between October 2018 to January 2020. Male predominance was observed in this case series, which is similar to the observation of Milhorat ${ }^{11}$ and Rahaman et al. ${ }^{12}$ Most patients in our study were from pediatrics and adolescent age group. In a meta-analysis by Issac et al, it is found that there is a U-shaped pattern across the age continuum in the prevalence of hydrocephalus, with an 8-fold decline from pediatrics to adults and a subsequent 17 -fold rise to the elderly. ${ }^{13}$ Although our study has less number of elderly patients than the adult age group, it may be due to the fact that surgery is already done in younger or adult age group and elderly people are mainly managed by medical treatment.

As much as $10.4 \%$ (47/454) of patients in our study were redo cases because of the complications of shunt surgery. The majority of patients among them were operated due to shunt obstruction. There were similar findings in the study by Pal et al. ${ }^{14}$

The most common cause of hydrocephalus in our study was found to be tumor-related obstruction. As per Issac, ${ }^{13}$ patients with brain tumors with or without surgical treatment experience an increased risk of hydrocephalus. In another study by Bir ${ }^{15}$ et al, tumor was also found to be an etiological factor in $30 \%$ of cases, in which hematologic malignancies (28.4\%) and gliomas (24.3\%) were the most associated lesions. Occurrence of other causes like NPH (4\%) and posttraumatic (4\%) are found in other similar studies. ${ }^{15,16}$ But some other studies ${ }^{4,14}$ have more number of congenital hydrocephalus than our study.

In our study, 90.3\% (410/454) of patients had no shunt-related postoperative complications at 3 months follow-up. Over the last 40 years, multiple study groups have reported a complication rate between 11 to $25 \%$ after VP shunt surgery. ${ }^{6,17-19}$ In this context, our results may suggest significant improvement of the VP shunt surgery complication over the last few decades. There could be various reasons for less complication, as we have used prophylactic antibiotics, 
antibiotic-impregnated shunt drape, trocar for abdominal placement of shunt, which avoided gross opening of the abdominal cavity, double gloves throughout the surgery and additional gloves were changed while doing ventriculostomy in all cases. Most of the cases were done in the elective operation theater, and we also used antibiotic-impregnated shunt in some cases. Langley et $\mathrm{al}^{20}$ in an analysis of controlled study found that prophylactic antibiotic therapy significantly reduced the rates of shunt infections, and a similar happening was experienced in the present study. Venes et al stressed the importance of meticulous prepping, draping, and aseptic operative technique. ${ }^{21}$

Most common shunt-related complications were found to be shunt blockage $(5.9 \% ; 27 / 454)$, followed by infection (3.1\%; 14/454). Paff et $\mathrm{al}^{9}$ already said that obstruction is the most common reason behind VP shunt malfunction and infection is the second most common reason, which was identical to our study findings. We have found that characteristics like age and gender did not affect the shunt function overall, which is comparable to the findings of Pal et al. ${ }^{14}$ None of congenital, posttraumatic, and NPH cases had any postoperative complications. Among 25 redo cases, 17 (68\%) patients had repeat shunt blockade. This finding is comparable to a study by Tuli et $\mathrm{a}^{22}$ and Jeyaselvasenthilkumar et al. ${ }^{23}$

Perforation of the bowel by catheter tubing may be a rare complication of VP shunt placement. It is estimated to occur at a rate of 0.1 to $0.7 \%{ }^{24}$ We had one case in our study. It had been primarily because of local infective adhesions and subsequent bowel wall erosion.

The navigation is often used intraoperatively to optimize the trajectory and final position of the proximal (ventricular) catheter in the ventricle, with the goal of good CSF drainage and less complication. We found that the neuronavigation actually decreases the risk of shunt failure, which is statistically significant $(p<0.05)$. Our finding is consistent with a study by Hermann ${ }^{25}$ and also with another study of the coauthor. ${ }^{26}$ But to recommend the routine use navigation system for the insertion shunt, we need a multicentric study with large sample size.

Ambekar et al..$^{27}$ and Kamat et $\mathrm{al}^{28}$ showed in their study that patients with increased protein levels in CSF are at a high risk of VP shunt blockage. In our study, we found more complications in the patients with elevated CSF protein of more than $40 \mathrm{mg}$ per deciliter. The excess protein secretion is either due to protein-secreting tumors or infective causes in case of TBM, which may lead to shunt blockade.

No cases of intraventricular hemorrhage were seen in our patients, which is way less the other studies (4\%). ${ }^{29}$ Though None of the biventricular shunt patients had any complications; among the single-sided shunt, left-sided had $34 \%$ had more infection by percentage and less on right side (5.9\%), although this was a statistically insignificant finding.

This study has certain limitations because of technical factors like different operating surgeons and preference of surgical techniques, which can affect present results. Shunt survival data for patients who were excluded because of missing records and noncompliance for follow-up might have skewed the results of our study. More long-term prospective studies focusing on the periodic evaluation of shunt and functional status may give more ideas on the predictors of shunt survival and long-term outcome.

\section{Conclusion}

Hydrocephalus is a neurological disorder common in both children and adults with majority toward pediatric and adolescent age group and mild male predominance. Primary etiology of hydrocephalus is tumor-related obstruction, followed by cerebral infection, although congenital hydrocephalus is not uncommon.

VP shunt placement has been considered the mainstay of management in hydrocephalus. The development of shunt surgeries has remarkably changed the end result in these patients with better potential of leading a natural life. VP shunts procedures are still associated with many complications. Shunt obstruction is the most common complication. Factors associated with increased shunt complications include redo and infective etiology and cases having higher protein in perioperative CSF analysis. Neuronavigation, antibiotic-impregnated shunt and biventricular shunt are associated with lower complications.

With continued advancements in shunt surgery and technologies and infection prevention, morbidity resulting from the complications continue to be reduced.

Funding

None.

\section{Conflict of Interest}

None declared.

\section{Acknowledgment}

The authors would like to acknowledge the Department of Neurosurgery and Department of Anesthesiology in the Institute of Medical Sciences at, Banaras Hindu University, Varanasi.

\section{References}

1 Fowler JB, De Jesus O, Mesfin FB. Ventriculoperitoneal Shunt. Treasure Island (FL): StatPearls Publishing; 2020

2 Pinto FCG, Saad F, Oliveira MF, et al. Role of endoscopic third ventriculostomy and ventriculoperitoneal shunt in idiopathic normal pressure hydrocephalus: preliminary results of a randomized clinical trial. Neurosurgery 2013;72(5):845-853, discussion 853-854

3 Sarguna P, Lakshmi V. Ventriculoperitoneal shunt infections. Indian J Med Microbiol 2006;24(1):52-54

4 Jaykar RD, Patil SP. Indications of ventriculoperitoneal shunt: a prospective study. Int Surg J 2017;4(4):1319-1326

5 Bloria SD, Bloria P, Kataria K. Anaesthesia for VP shunt surgery. Karnataka Anaesth J 2017;3:1-3

6 Reddy GK, Bollam P, Caldito G. Long-term outcomes of ventriculoperitoneal shunt surgery in patients with hydrocephalus. World Neurosurg 2014;81(2):404-410

7 Stone JJ, Walker CT, Jacobson M, Phillips V, Silberstein HJ. Revision rate of pediatric ventriculoperitoneal shunts after 15 years. J Neurosurg Pediatr 2013;11(1):15-19 
8 McGirt MJ, Leveque JC, Wellons JC III, et al. Cerebrospinal fluid shunt survival and etiology of failures: a seven-year institutional experience. Pediatr Neurosurg 2002;36(5):248-255

9 Paff M, Alexandru-Abrams D, Muhonen M, Loudon W. Ventriculoperitoneal shunt complications: A review. Interdiscip Neurosurg 2018;13:66-70

10 Rahalkar MD. Complications of cerebrospinal fluid diversion (shunt) catheters: a pictorial essay. Indian J Neurosurg 2018;07(1):58-76

11 Lemire RJ. Hydrocephalus and the cerebrospinal fluid. Thomas H. Milhorat. Williams and Wilkins Co., Baltimore. 237 pp. 1972. Teratology 1974;9(1):128-128

12 Rahman MM, Haque MA, Islam MR, et al. Demographic characteristics and etiology of hydrocephalus patients attended at tertiary care hospital in Bangladesh. J Natl Inst Neurosci Bangladesh 2015;1(2):47-49

13 Isaacs AM, Riva-Cambrin J, Yavin D, et al. Age-specific global epidemiology of hydrocephalus: Systematic review, metanalysis and global birth surveillance. PLoS One 2018;13(10):e0204926

14 Pal SS, Dubey S. A study of VP shunt in management of hydrocephalus. Int Surg J 2017;4(5):1697-1701

15 Bir SC, Patra DP, Maiti TK, et al. Epidemiology of adult-onset hydrocephalus: institutional experience with 2001 patients. Neurosurg Focus 2016;41(3):E5

16 Riva-Cambrin J, Kestle JRW, Holubkov R, et al. Hydrocephalus Clinical Research Network. Risk factors for shunt malfunction in pediatric hydrocephalus: a multicenter prospective cohort study. J Neurosurg Pediatr 2016;17(4):382-390

17 George R, Leibrock L, Epstein M. Long-term analysis of cerebrospinal fluid shunt infections. A 25-year experience. J Neurosurg 1979;51(6):804-811

18 Korinek AM, Fulla-Oller L, Boch AL, Golmard JL, Hadiji B, Puybasset L. Morbidity of ventricular cerebrospinal fluid shunt surgery in adults: an 8-year study. Neurosurgery 2011;68(4):985-994, discussion 994-995
19 Khan F, Rehman A, Shamim MS, Bari ME. Factors affecting ventriculoperitoneal shunt survival in adult patients. Surg Neurol Int 2015;6:25

20 Langley JM, LeBlanc JC, Drake J, Milner R. Efficacy of antimicrobial prophylaxis in placement of cerebrospinal fluid shunts: meta-analysis. Clin Infect Dis 1993;17(1):98-103

21 Venes JL. Control of shunt infection. Report of 150 consecutive cases. J Neurosurg 1976;45(3):311-314

22 Tuli S, Drake J, Lawless J, Wigg M, Lamberti-Pasculli M. Risk factors for repeated cerebrospinal shunt failures in pediatric patients with hydrocephalus. J Neurosurg 2000;92(1):31-38

23 Jeyaselvasenthilkumar TP, Ramesh VG, Sekar C, Sundaram S. A study to formulate a strategy to prevent ventriculoperitoneal shunt infection. Indian J Neurosurg 2015;04(2):74-79

24 Snow RB, Lavyne MH, Fraser RA. Colonic perforation by ventriculoperitoneal shunts. Surg Neurol 1986;25(2):173-177

25 Hermann EJ, Polemikos M, Heissler HE, Krauss JK. Shunt surgery in idiopathic intracranial hypertension aided by electromagnetic navigation. Stereotact Funct Neurosurg 2017;95(1):26-33

26 Sahu A, Shende N, Singh Kulwant, et al. Evaluation Of Ventriculoperitoneal Shunt Surgery Through Conventional And Ventriculoscopic Technique. Journal of Evolution of Medical and Dental Sciences 2017;6:136-140. DOI: 10.14260/ Jemds/2017/33

27 Ambekar S, Srinivas D, Pandey P, Sampath S, Bangalore CA, Indira DB. Factors influencing shunt malfunction in patients with tuberculous meningitis. Indian J Neurosurg 2013;02(2):175-181

28 Kamat AS, Gretschel A, Vlok AJ, Solomons R. CSF protein concentration associated with ventriculoperitoneal shunt obstruction in tuberculous meningitis. Int J Tuberc Lung Dis 2018;22(7):788-792

29 Savitz MH, Bobroff LM. Low incidence of delayed intracerebral hemorrhage secondary to ventriculoperitoneal shunt insertion. J Neurosurg 1999;91(1):32-34 